\title{
Sonic Motor Pathways in Piranhas with a Reassessment of Phylogenetic Patterns of Sonic Mechanisms among Teleosts
}

\author{
Friedrich Ladich ${ }^{a}$ Andrew H. Bass ${ }^{b}$ \\ ${ }^{a}$ Department of Neurobiology and Behavior, University of Vienna, Vienna, Austria; \\ ${ }^{b}$ Department of Neurobiology and Behavior, Cornell University, Ithaca, N.Y., USA
}

\section{Key Words}

Sonic motor pathways - Sound production - Swim bladder muscles · Sonic mechanisms · Spinal motor neurons $\cdot$ Piranhas $\cdot$ Teleost fishes

\begin{abstract}
Sound production has evolved independently a number of times among teleost fishes. In most cases, sound is generated by fast contracting muscles that vibrate the swim bladder by way of their direct attachment (intrinsic muscles) or indirectly by way of other skeletal elements (extrinsic muscles). This study focuses on the red and black piranha, Pygocentrus nattereri and Serrasalmus rhombeus (superorder Ostariophysi, Order Characiformes), that have extrinsic swim bladder sonic muscles innervated by the third and fourth spinal nerves. This innervation pattern diverges from that found in most teleosts, including the closely related catfishes (Ostariophysi, Siluriformes), where sonic muscles are innervated by ventral occipital nerve roots that arise just caudal to the vagus nerve. Here, we tested the hypothesis that piranhas would also differ from most other teleosts in the location of their sonic motor neurons. Following biotin labeling of branches of the third and fourth spinal nerves that innervate the sonic muscles in the red and black piranha, sonic motor neurons were identified amongst
\end{abstract}

other non-sonic motor neurons in the central part of the spinal cord, slightly ventrolateral to the central canal. To our knowledge, this is the first example of sonic motor neurons positioned entirely within the spinal cord. In the other species so far studied, sonic motor neurons form well-defined nuclei that extend from far caudal levels of the medulla into the rostral spinal cord and are located either within the ventral motor column or near the midline, close to or just ventrolateral to the fourth ventricle and central canal. A piranha-like pattern may be more widespread among characiforms and is likely present in other teleost orders, e.g., Sciaenidae (drumfishes), that also have sonic muscles innervated by spinal nerves.

Copyright (C) 2005 S. Karger AG, Basel

\section{Introduction}

Teleost fishes exhibit the widest diversity of sound generating (sonic) mechanisms among vertebrates [for recent reviews see Ladich and Bass, 2003; Ladich, 2004; Ladich and Fine, in press]. Although sound production apparently evolved independently among several distantly related groups, most species have a sonic mechanism dependent on fast-contracting sonic muscles that vibrate the gas-filled swim bladder. However, species exhibit a wide range of variation in the origin and insertion of the sonic

\section{KARGER}

(C) 2005 S. Karger AG, Basel

Fax +41613061234 E-Mail karger@karger.ch www.karger.com www.karger.com/bbe
Friedrich Ladich

Department of Neurobiology and Behavior

University of Vienna, Althanstrasse 14

AT-1090 Vienna (Austria)

Tel. +4314277 54227, Fax +4314277 9544, E-Mail friedrich.ladich@univie.ac.at 
muscles. For example, osteoglossomorphs (weakly electric mormyrids), batrachoidiforms (toadfish and midshipman fish), some scorpaeniforms (sea robins) and gadiforms (cods), have sonic muscles attached to the walls of the swim bladder that are often referred to as intrinsic muscles [Hallacher, 1974; Bass, 1985; Bass and Baker, 1991; Hawkins, 1993; Crawford and Huang, 1999]. Among siluriforms (catfishes), some scorpaeniforms (rockfishes), beryciforms (squirrelfishes), and perciforms (tigerfishes and drumfishes), sonic muscles originate on the skull, a vertebral process, or the cleithrum, and insert either directly on the swim bladder or vibrate it indirectly via either tendons or bones; these muscles are often referred to as extrinsic [Winn and Marshall, 1963; Schneider, 1964; Ono and Poss, 1982; Hawkins, 1993; Ladich and Bass, 1998; Takayama et al., 2003]. A second category of sonic mechanisms depends upon the vibration of either the pectoral fins or girdle, including, e.g., the rubbing of an enhanced pectoral spine within cleithral grooves in catfishes [reviewed in Fine and Ladich, 2003], snapping of enlarged pectoral fin tendons in gouramis [Kratochvil, 1978], drumming of membranes [Salmon et al., 1968], and vibration of the pectoral girdle in sculpin and cod [Barber and Mowbray, 1956; Ladich, 1989]. Sounds can also be produced by various other structures such as pharyngeal teeth [Lanzing, 1974], neck vertebrae [Fish, 1953] and gas expulsion [Wilson et al., 2004], but these mechanisms have not been described in detail.

Neuroanatomical studies have identified two major patterns of organization for sonic motor neurons [for review, see Ladich and Bass, 1998; Carlson and Bass, 2000]. One pattern exhibits motor neurons positioned close to the midline, near the fourth ventricle and central canal in the caudal medulla and rostral spinal cord. This includes the mormyrid Brienomyrus [Bass, 1985], batrachoidiforms [see Bass and Baker, 1991], siluriforms [pimelodid, ariid, mochokid and doradid catfishes; Ladich and Fine, 1994; Ladich and Bass, 1996, 1998]. A second pattern showing sonic motor neurons that have a similar rostralcaudal extent within the ventral motor column has been identified among scorpaeniforms [scorpaenids, triglids and cottids; Bass, 1985; Finger and Kalil, 1985; Bass and Baker, 1991; Ladich and Bass, 1998; Yoshimoto et al., 1999], beryciforms [holocentrids; Carlson and Bass, 2000] and perciforms [osphronemids; Ladich and Fine, 1992]. Pimelodid catfish have both a midline population of motor neurons associated with a sonic swim bladder mechanism and a ventrolateral population associated with a pectoral spine mechanism [Ladich and Fine, 1994].
Within the superorder Ostariophysi, sound production is known for several species of cypriniforms and characiforms (e.g., prochilodontids, curimatids), but is best known in catfishes (Siluriformes, several families) and the piranhas (Characiformes, family Characidae). Although catfishes and piranhas achieve sound production by a sonic swim bladder mechanism, they vary in the origin and insertion of the sonic muscles. Among catfishes, the swim bladder is vibrated either directly by sonic muscles inserted at the bladder such as in pimelodids or indirectly via a differently-shaped thin bony plate, the elastic spring, in ariids, mochokids and doradids [Ladich and Fine, 1994; Ladich and Bass, 1998; Ladich, 2001, reviewed in Fine and Ladich, 2003]. Piranhas have sonic muscles that originate on the vertebral column and insert on a broad tendon surrounding the ventral aspect of the swim bladder [Markl, 1971]. Contractions of the sonic muscles pull the tendon dorsally, resulting in a compression of the bladder and the emission of brief, low frequency, harmonic sounds [Ladich, 1999]. Catfishes and piranhas also differ in the innervation of the sonic muscles. Among catfishes, and most other species so far examined that have a sonic swim bladder mechanism, the sonic muscles are innervated by occipital nerve roots or occipital and spinal nerves that exit the caudal hindbrain and rostral spinal cord [Tavolga, 1962; Ladich and Fine, 1994]. The one exception to this pattern is among sciaenids that have true spinal innervation [Ono and Poss, 1982; Vance et al., 2002]. Markl [1971] reports that the drumming muscles in the red piranha, Pygocentrus nattereri, are innervated by the first two spinal nerves. Given the divergence in the sonic muscle innervation pattern between catfishes and piranhas, we tested the hypothesis that these two groups would also diverge in the position and extent of sonic motor neurons in the central nervous system. Biotin compounds were used as neuroanatomical tracers to identify sonic motor neurons in two species of piranhas from different genera: the red piranha, $P$. nattereri, and the black piranha, Serrasalmus rhombeus. Given this new information, we reassessed phylogenetic trends in central and peripheral mechanisms of sound production among teleosts by comparing the diversity in organization of vocal/sonic motor systems among ostariophysines to that of other distantly related teleosts [our use of the term 'vocal' implies specific comparisons to sonic mechanisms in tetrapods; see Bass and Baker, 1997]. 


\section{Materials and Methods}

A total of 12 piranhas were used in this study: five red piranhas, Pygocentrus nattereri (44.5-61 g), and seven black piranhas, Serrasalmus rhombeus (24.4-33.5 g). All fish were obtained commercially (Seven Star Tropical, 2444 Jasper St., Philadelphia, Pa, USA, 19125 ) and maintained in groups of five to six individuals at $25^{\circ} \mathrm{C}$ in aerated and filtered aquaria. This research was performed under the guidelines established by the National Institute of Health and the Cornell University Institutional Animal Care and Use Committee.

Sounds were recorded using a digital audio tape recorder (HHB PDR 100), a hydrophone (Brüel \& Kjaer 8101), a power supply (Brüel \& Kjaer 2804) and analyzed using STx 2.17, the Integrated Software for Acoustics, Speech, and Signal Processing developed by the Institute of Sound Research of the Austrian Academy of Sciences, Vienna. Immunocytochemical and surgical procedures followed those of Bass et al. [1994] and Ladich and Bass [1996]. Fish were anesthetized with $0.01 \%$ benzocaine $(0.1 \mathrm{~g} / 1)$. For sonic nerve labeling, a 1-2 cm incision was made just caudal to the operculum, followed by exposure of the distal ends of the spinal nerves and their branches that innervate the sonic muscle (see fig. 1). The sonic nerve branches were completely severed, placed upon a piece of parafilm, and crystals of either neurobiotin (Sigma, St. Louis, Mo., USA) or biotin dextran-amine (10 kD, Molecular Probes, Eugene, Oreg., USA) were applied to their proximal ends using a minutien insect pin. After about $15 \mathrm{~min}$, the parafilm was removed, and the exposed area blotted dry. The incision was closed with 6-0 suture thread and then sealed with Vetbond (3M, St. Paul, Minn., USA). Animals were returned to their home aquarium for recovery. A total of 10 red and black piranhas were included in the experimental portion of this study; an additional red and black piranha were used for dissection to identify the position of the sonic muscle and nerves. Spinal nerves 3 and 4 (and 6 in black piranha) have sonic and non-sonic branches (see Results and fig. 1). The 10 experimental animals included four with only a non-sonic branch of one or more spinal nerves labeled, four with only the sonic branch of nerves 3 and 4 labeled, and two with the sonic and non-sonic branches of 3 and 4 labeled on opposite sides of the body. There were no apparent differences in labeling pattern with either neurobiotin or with biotin dextran-amine. After survival times of 2-4 days, animals were deeply anesthetized in $0.01 \%$ benzocaine and then perfused transcardially with cold teleost Ringer's solution followed by $4 \%$ paraformaldehyde dissolved in $0.1 \mathrm{M}$ phosphate buffer (PB). Brains were removed and postfixed for about $1 \mathrm{~h}$, stored in $0.1 \mathrm{M}$ phosphate buffer, and transferred to $30 \%$ sucrosephosphate buffer about $15 \mathrm{~h}$ prior to sectioning. Either transverse or horizontal sections were cut frozen at $50 \mu \mathrm{m}$ and processed as follows: (1) $30 \mathrm{~min}$ incubation in $0.4 \%$ Triton- $X$ in phosphate buffered saline; (2) $3 \mathrm{~h}$ incubation in an avidin-biotinylated horseradish peroxidase (HRP) complex (Elite Kit, Vector Laboratories, Burlington, Calif., USA); (3) Two 10-min rinses in PB; (4) 1-2 min incubation in $0.05 \%$ diaminobenzidine (DAB), $0.01 \%$ hydrogen peroxide dissolved in PB (visualized for reaction product); (5) two rinses in PB. Sections were then stored in PB until they were mounted on chrom-alum subbed slides. Slides were lightly counterstained with cresyl violet, dehydrated in a graded series of alcohol, and coverslipped.

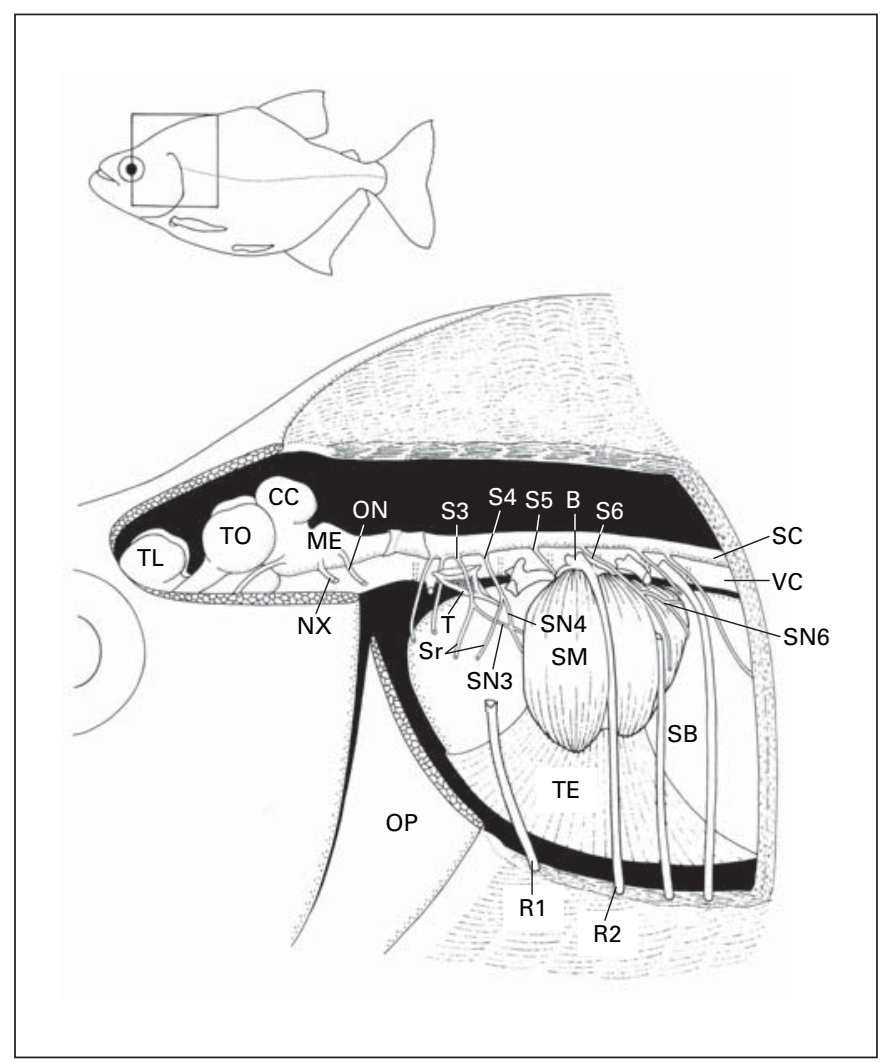

Fig. 1. Line drawing of a lateral view of the entire fish and the postcranial region (inset) in a black piranha $S$. rhombeus showing the sonic muscle (SM). The first and third pleural ribs were partly removed in order to show the innervation. Abbreviations: $\mathrm{B}=$ enlargement at the base of the second rib, $\mathrm{CC}=$ cerebellum, $\mathrm{ME}=$ medulla oblongata, $\mathrm{NX}=$ vagal nerve, $\mathrm{ON}=$ occipital nerve, $\mathrm{OP}=$ operculum, R1, 2 = ribs, S3, 4, 5, $6=$ spinal nerves, $\mathrm{SB}=$ swim bladder, $\mathrm{SC}=$ spinal cord, $\mathrm{SM}=$ sonic muscle, $\mathrm{SN} 3,4,6=$ sonic nerves, $\mathrm{Sr}=$ rostral branches of spinal nerves, $\mathrm{T}=$ Tripus, $\mathrm{TE}=$ sonic muscle tendon, $\mathrm{TL}=$ telencephalon, $\mathrm{TO}=$ optic tectum, $\mathrm{VC}=$ vertebral column.

\section{Results}

\section{Sound Generating Mechanism}

The sound-generating mechanism in black and red piranhas includes sonic muscles that originate on transverse expansions at the base of the second rib and insert on a broad tendon that widens as it surrounds the ventral aspect of the swim bladder. The sonic muscle is round in shape and attaches to the tendon dorsal and lateral to the wall of the swim bladder (fig. 1). The muscle extends between the first and fourth pleural ribs in S. rhombeus and between the first and third ribs in $P$. nattereri. The second and third ribs are pressed into these muscles laterally, 


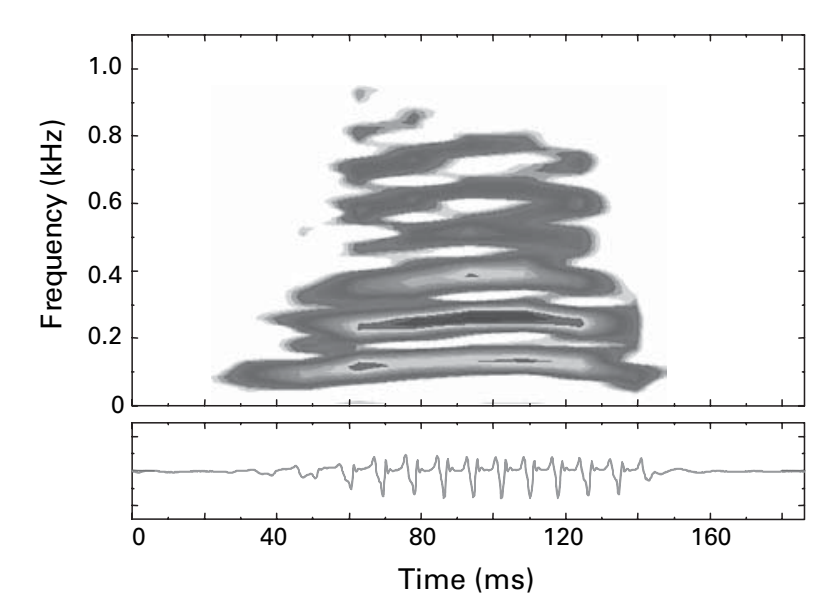

Fig. 2. Sonagram and oscillogram of a drumming sound of the red piranha $P$. nattereri uttered under hand-held conditions. Sampling frequency $16 \mathrm{kHz}$, filter bandwidth $30 \mathrm{~Hz}, 50 \%$ overlap.

thus resulting in superficial partitionings. All sonic muscle fibers extend dorso-ventrally and originate only on the second rib.

When held by hand, piranha produce low-frequency, harmonic sounds of approximately $100-150 \mathrm{~ms}$ in duration, with a fundamental frequency that varies between 100 and $150 \mathrm{~Hz}$ (e.g., P. nattereri; fig. 2); the fundamental frequency is determined by the sonic muscle contraction rate [see Kastberger, 1981a, b].

\section{Innervation}

The sonic muscle in both species is innervated by branches of the third and fourth spinal nerves (S3, S4; fig. 1). Caudal branches of these nerves (SN3, SN4; fig. 1) join before two smaller branchlets enter the cranial aspect of the sonic muscle. Rostral, non-sonic branches of S3 and S4 (Sr; fig. 1) innervate trunk muscles. The fifth spinal nerve (S5; fig. 1) extends between the swim bladder and the sonic muscle ventrally, but it is unclear if it innervates the muscle. The sixth spinal nerve (S6; fig. 1) extends lateral to the drumming muscle and parallel to the rib ventrally. A caudal branch of this nerve innervates the drumming muscle caudally in black piranhas (SN6; fig. 1).

\section{Sonic Motor Neurons}

Application of either neurobiotin or biotin dextranamine to the sonic branches of S3 and S4 resulted in ipsilateral labeling of motor neurons that overlapped in their rostral-caudal extent with the exiting spinal roots that carried their labeled axons (e.g., fig. 3A). Filled somata were not clustered into a discrete nucleus, but rather overlapped in their extent with other unlabeled, apparently non-sonic, motor neurons. Labeled neurons were located near the midline just ventral to the central canal (CC; fig. 3), and extended along the lateral margin of the medial longitudinal fasciculus (MLF; fig. 3). Motor neurons were not labeled along the lateral margin of the ventral fasciculus (FV; fig. 3). The largest cells that were labeled were positioned just lateral to the dorsal aspect of the medial longitudinal fasciculus. However, the very largest cells at these same spinal levels (e.g., double arrowheads, fig. 3A, C) were never labeled and likely innervate non-sonic, epaxial muscles [see Finger and Kalil, 1985; Carlson and Bass, 2000]. Sonic motor somata varied in shape from fusiform to ovoid (fig. 3A-F) and their dendrites extended either laterally or dorsolaterally, depending on their position along the medial longitudinal fasciculus, toward a site lateral to the dorsal aspect of the medial longitudinal fasciculus (e.g., fig. 3B). Horizontal sections suggested that the dendrites branched extensively at this lateral site along the rostral-caudal axis (fig. 3E). Motor neuron axons extended unbranched, ipsilaterally along the lateral margin of the medial longitudinal fasciculus (e.g., single arrowhead, fig. 3C) before entering a ventral spinal root (S3; fig. 3A).

\section{Non-Sonic Motor Neurons}

Labeling of non-sonic branches of spinal nerves 3 and 4 labeled clusters of motor neurons close to the border between the medial longitudinal and ventral fasciculi (left side, fig. 3F). Labeled cells were mainly fusiform in shape; the very largest motor neurons near the central canal (e.g., fig. 3A, C) were never labeled in these cases; we assume their axons exit via spinal nerve branches that innervate

Fig. 3. Photomicrographs of labeled sonic motor neurons following biotin application to the sonic and non-sonic branches of the third and fourth spinal nerves in black (A, B, F) and red (C-E) piranha. Transverse (A-D, F) and horizontal (E) sections were lightly counterstained with cresyl violet. Scale bar represents $200 \mu \mathrm{m}$ in $\mathbf{A}$ and $100 \mu \mathrm{m}$ in B for B-F. A Low-power photomicrograph showing bilateral labeling of spinal nerves (S3) following bilateral labeling of sonic branches (SN3) with biotin dextran-amine; a labeled sonic motor neuron is also shown here (left side) with its somata positioned just ventral and lateral to the central canal (CC). A more dorsal, large, unlabeled motor neuron is also indicated (double arrowheads). B Biotin dextran-amine labeled sonic motor neurons showing their dendrites extending dorsal and lateral towards a site where there is abundant labeling (likely the dendrites of other motor neurons that extend along the rostral-caudal axis, see E). C Bio- 

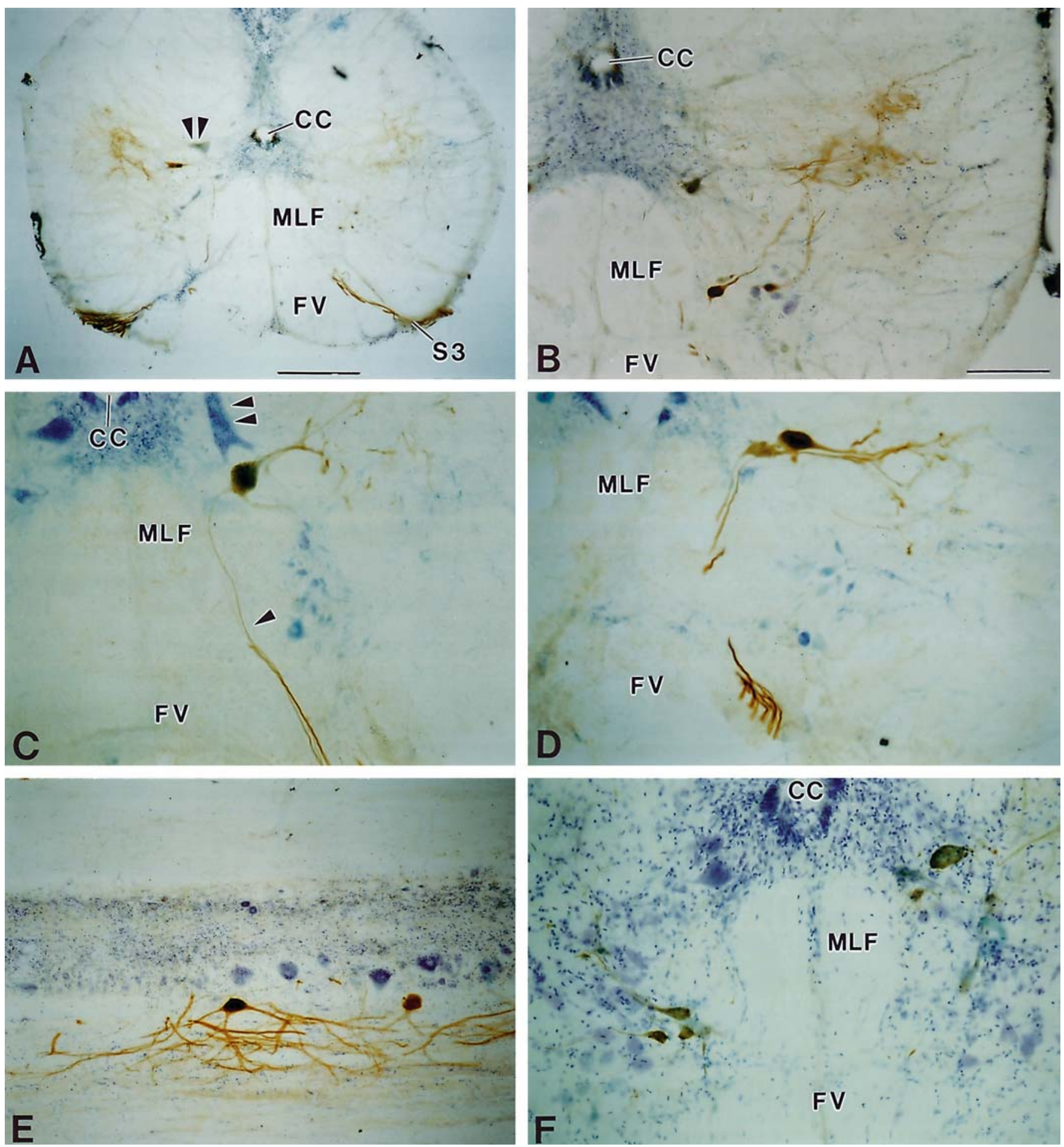

tin dextran-amine labeling of an ovoid-shaped sonic motor neuron soma showing its laterally projecting dendrites and its unbranched axon (single arrowhead) extending along the lateral margin of the medial longitudinal fasciculus (MLF) and ventral fasciculus (FV). A nearby unlabeled, large motor neuron is also indicated (double arrowheads). D Biotin dextran-amine labeling of fusiform-shaped sonic motor neuron somata and their laterally projecting dendrites

and medially projecting axons extending along the lateral margin of the MLF; other labeled axons are apparent along the lateral margin of the FV. E Neurobiotin labeling of sonic motor neurons and their dendrites extending along the rostral (left)-caudal axis; other medially positioned motor neurons are unlabeled. F Biotin dextranamine labeling of non-sonic (left) and sonic (right) motor neuron somata. 

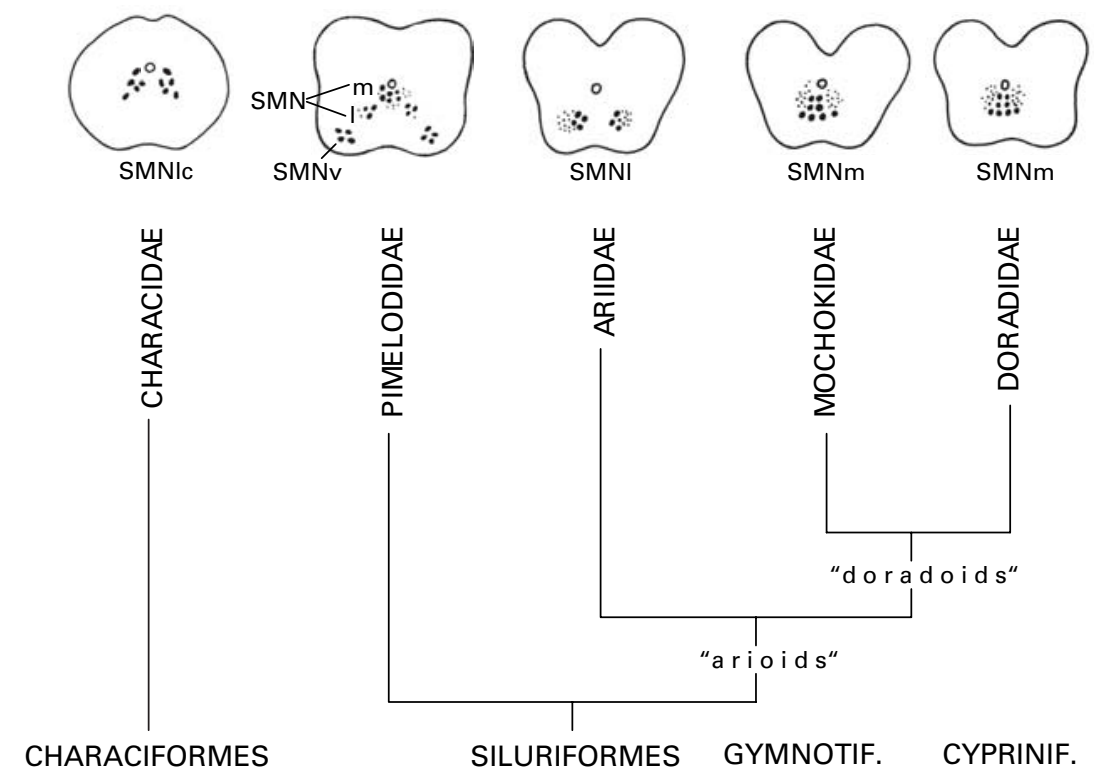

岩

岩

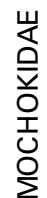

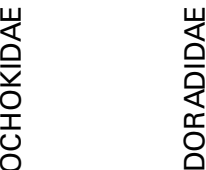

|

(
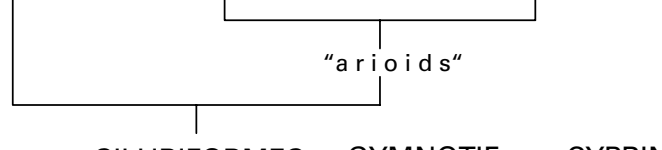

CHARACIFORMES

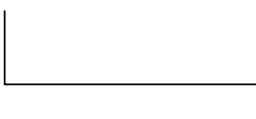

A

Ostariophysi
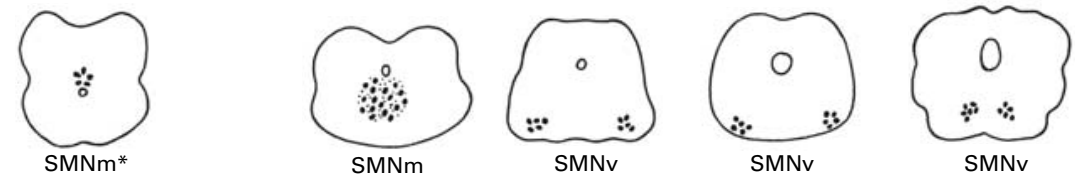

Fig. 4. Cladistic relationships among teleostean families with identified patterns of organization for the sonic motor nucleus [systematics after Lundberg, 1993; Nelson, 1994; Fink and Fink, 1996]. Abbreviations indicate relative position of sonic motor neurons: central lateral (SMNlc), lateral (SMN1), and medial (SMNm) and ventral (SMNv). The only mormyrid studied so far is not known to be sonic, and the SMNm is therefore putative (asterisk) [modified from Ladich and Bass, 1998; Carlson and Bass, 2000].

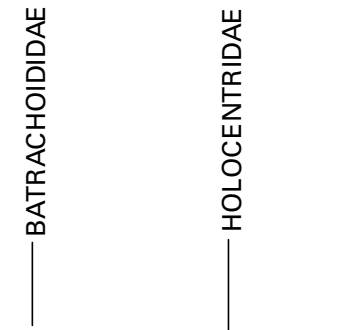

BATRACHOIDIF. BERYCIF.

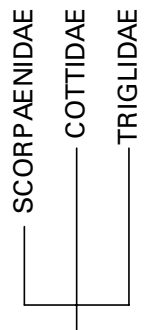

MORMYRIF.

PERCIF.

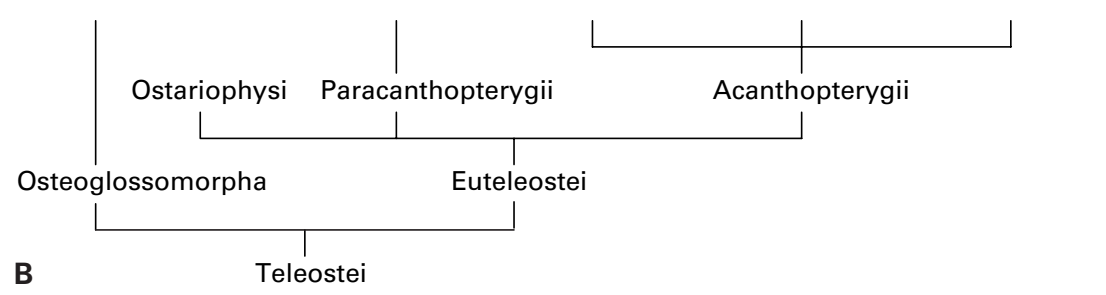


epaxial muscle. Non-sonic motor neurons were found at the same rostral-caudal level as sonic motor neurons, as best demonstrated in the animals that had sonic and nonsonic branches of nerves 3 and 4 labeled on opposite sides of the body (fig. 3F). Sonic and non-sonic motor neurons also appear to be adjacent to one another at the border between the medial longitudinal fasciculus and ventral fasciculus (compare the left side of fig. 3F to the more ventral sonic motor neurons labeled in 3B). Together, the results show that sonic motor neurons do not form a discrete motor nucleus but rather overlap non-sonic motor neurons at the same rostral-caudal and dorsal-ventral levels of the spinal cord.

\section{Discussion}

\section{Sonic Organs and Motor Neurons in Ostariophysi}

Among ostariophysines, the Cypriniformes are considered the sister group of all other groups with Siluriformes and Gymnotiforms being more closely related to each other [termed Siluriphysi by Fink and Fink 1996; fig. 4A]. Sound production is known for a few representative members of the Cypriniformes [Stout, 1963; Ladich, 1988; Johnston and Johnson, 2000] but the sonic mechanisms remain unknown. Among catfishes and characiforms, but not gymnotiforms, numerous sound generating mechanisms have evolved [Ladich and Bass, 1998; Fine and Ladich, 2003; Ladich and Fine, in press]. In the representatives of at least seven families of catfishes (pimelodids, ariids, doradids, auchenipterids, mochokids, pangasiids, malapterurids), sonic muscles associated with the swim bladder are utilized to produce low frequency drumming sounds. At least four mechanisms of swim bladder vibration have been distinguished [for a recent review see Fine and Ladich, 2003]. In pimelodids, sonic muscles originate on a transverse process of the vertebral column and insert ventrally on the swim bladder. In all other families, swim bladders are vibrated by diverse bony plates termed elastic springs, which are rapidly pulled forward by sonic muscles. Some catfishes are also able to produce broad-band, stridulatory sounds by rubbing the base of their pectoral spines in a groove of the shoulder girdle [Ladich, 1997; Fine et al., 1999].

Among Characiformes, sound generating mechanisms are best known in piranhas [family Characidae; Markl, 1971]. Brief descriptions of sonic organs are known from representatives of other families. Schaller and Kratochvil [1981] described intercostal muscles in males of the jaraqui, Semaprochilodus (Prochilodus) insignis (family Pro- chilodontidae), and the branquinha, Potamorhinus (Anodus) laticeps (family Curimatidae), which differ in origin and insertion. These few observations point to a wide diversity of sonic mechanisms in Characiformes that differ from those known in catfishes where sonic muscles affect swim bladder vibration by way of either direct attachment or indirectly via an elastic spring mechanism (see above). In the two genera of piranhas studied here, Pygocentrus and Serrasalmus, sonic muscles originate on the extended base of one rib and not on transverse processes of several vertebra as suggested by Markl [1971]. Contrary to Markl [1971], we show that the sonic muscle inserts on a broad tendon that widens ventrally and covers almost the entire anterior part of the swim bladder. The muscles do not insert on a small tendon band as shown by Markl but on a broad tendon which was also demonstrated by Stabentheiner [1988] in the red piranha.

Sonic motor pathways also differ between piranhas and the closely related catfishes. Sonic swim bladder muscles in piranhas are innervated by spinal nerves and in catfishes by occipital nerves; sonic muscles in pimelodid catfish are innervated by occipital and spinal nerves [Ladich and Fine, 1994]. Here, we show that the sonic muscles are innervated by the third and fourth spinal nerve in both the red and black piranha and most likely by the sixth in the black piranha; the first two spinal nerves are clearly not involved in the innervation. The possible homologies among post-vagal, i.e., occipital nerves in fishes have been controversial since the $19^{\text {th }}$ century [see summary in Tavolga, 1962]. Post-vagal nerves emerging from the skull are typically regarded as occipital nerves, whereas those exiting at vertebral levels are regarded as spinal nerves. Sonic motor neurons lie more anterior in catfishes, extending from the caudal medulla into the very rostral spinal cord, consistent with the innervation of their sonic muscles by occipital nerves [Ladich and Fine, 1994; Ladich and Bass, 1996, 1998]. The position of sonic motor neurons entirely within the spinal cord in piranhas is consistent with the innervation of their sonic muscles by post-occipital nerve roots; an entirely spinal location has not been previously described in any other ostariophysine (or teleost) taxon. Among catfish, sonic motor neurons vary in their position relative to the midline. Motor neurons form a distinct nucleus on the midline in mochokids and doradids (SMNm; fig. 4A), both on the midline and slightly more ventrolateral in pimelodids (SMNl; fig. 4A), and only ventrolateral to the midline in ariids [SMNl; fig. 4A; Ladich and Fine, 1994; Ladich and Bass, 1996, 1998]. Although not forming a distinct motor nucleus as in catfishes, the sonic motor neurons in 
piranhas essentially overlap this topographical range and extend from a centrolateral to a more ventrolateral position. The lack of a distinct motor nucleus may be a shared trait with other species that have their sonic motor neurons positioned entirely within the spinal cord.

\section{Comparisons between Ostariophysi and Acanthopterygii}

Among the Acanthopterygii, sound generating mechanisms and vocal pathways have been described in representatives of five families from three orders - Beryciformes, Scorpaeniformes and Perciformes (see fig. 4B). Like siluriforms, scorpaeniforms exhibit a range of sonic organs, but this diversity differs from that of siluriforms in that interfamilial and intergeneric variations are more pronounced. Despite a large variety of sonic mechanisms, there is a conserved pattern of organization for the sonic motor neurons in scorpaeniforms that is consistent with the involvement of pectoral elements in the sonic mechanism [see Ladich and Bass, 1998, for extended discussion]. Thus, sonic motor neurons are located in the ventral motor column in scorpaenids, cottids and triglids [SMNv; fig. 4B; Bass and Baker, 1991; Ladich and Bass, 1998; Yoshimoto et al., 1999]. This pattern resembles that observed for the pectoral spine motor neurons in pimelodid catfish [SMNv; fig. 4B; Ladich and Fine, 1994].

Holocentrids (squirrelfishes; order Beryciformes) also have extrinsic sonic swim bladder muscles and sonic motor neurons located ventrolaterally in the caudal medulla and rostral spinal cord as in scorpaeniforms [SMNv; fig. 4B; Carlson and Bass, 2000]. Within the largest teleost order, the Perciformes, a diversity of sound producing mechanisms has evolved [Takayama et al., 2003; Ladich and Fine, in press]. Among labyrinth fishes (suborder Anabantoidei, family Osphronemidae) representatives of the genus Trichopsis (croaking gouramis) have modified pectoral fins for sound production [Kratochvil, 1978] and sonic motor neurons positioned within the ventral motor column [SMNv; fig. 4B; Ladich and Fine, 1992], like the pectoral fin motor neurons in siluriforms and sonic motor neurons in scorpaeniforms and beryciforms. The similar location for sonic motor neurons in all five families of Acanthopterygii suggests a conserved pattern of organization within this superorder. However, this conclusion may be premature given the lack of information for some of the major sound producing families among Perciformes including serranids, sciaenids and gobiids. Sciaenids and drums may be especially important in this regard because they possess sonic muscles that lack a con- nection to skeletal elements, are derived from hypaxial muscles and are innervated by post-occipital spinal nerves [Ono and Poss, 1982; Vance et al., 2002]. As observed here for piranhas, preliminary data suggest that sonic motor neurons in sciaenids are located near the central canal and overlap the position of epaxial and hypaxial trunk motoneurons [CA Hyman, LAD Williams and ML Fine, pers. comm.].

\section{Comparison between Ostariophysi, Acanthopterygii} and Paracanthopterygii

Among Paracanthoptergygii, there is little variation in sonic organ architecture in batrachoidiforms (midshipman fish and toadfish) that have intrinsic swim bladder muscles that mainly differ in the extent of their attachment to the lateral walls of the swim bladder [reviewed in Bass and Baker, 1991]. Gadiformes include species with either intrinsic or extrinsic swim bladder muscles [Hawkins, 1993], but sonic motor neurons have not been identified. Amongst teleosts in general, central mechanisms have been best studied among batrachoidids that have an extensive, midline-positioned sonic motor nucleus [reviewed in Bass and Baker, 1991; SMNm; fig. 4]. Premotor, pacemaker-like neurons form a column along the ventrolateral margin of the sonic motor nucleus [Bass and Baker, 1990; Bass et al., 1994, 1996] and are activated by a vocal motor network distributed at hindbrain, midbrain and forebrain levels [Bass et al., 1994; Goodson and Bass, 2002].

Transneuronal neurobiotin transport identified premotor neurons in mochokid catfishes within the dorsolateral region of, and just rostral to, the sonic motor nucleus [Ladich and Bass, 1996]. The premotor neurons within the sonic motor nucleus is similar in location to the pacemaker neurons of batrachoidids. Carlson and Bass [2000] identified premotor neurons in squirrelfishes (family Holocentridae) that overlap the position of sonic motor neurons, whereas Yoshimoto et al. [1999] identified premotor neurons in rockfishes (family Scorpaenidae) that were localized rostral to the sonic motor neurons within the reticular formation and the descending octaval nucleus. Although we did not identify premotor neurons in piranhas, Kastberger [1981b] showed that electrical stimulation within the medulla in S. spilopleura elicited a rhythmic motor output whose firing rate was independent of stimulus frequency, suggesting a pacemaker-like nucleus in the medulla. Importantly, the rate and duration of the motor volley coincided well with the pulse rate and duration of behavioraly elicited drumming sounds from the same individual as found in the extensively studied batrachoidids (see above references). 


\section{Evolutionary and Developmental Considerations}

The new information presented here on the position of sonic motor neurons within post-occipital regions of the spinal cord now shows a third major pattern of organization for these motor neurons among teleost fish. As reviewed above, the other two patterns are the midline sonic motor nucleus of batrachoidiforms and siluriforms and the ventral motor nucleus of acanthopterygians that extend from the caudal medulla into the rostral spinal cord; in both of these cases, the sonic muscles are innervated by occipital nerve roots. The common innervation of the sonic muscle by occipital nerve roots in these teleost groups suggests a common developmental origin for the muscle, namely from occipital somites that migrate together with occipital nerve axons to a location either adjacent to or attached to the swim bladder as shown for batrachoidids [Tracy, 1959, 1961; Lindholm and Bass, 1993; Rauther, 1945, showed that sonic muscles in scor- paeniforms develop from anterior hypaxial musculature that may be equivalent to occipital somites]. Although it seems unlikely that sonic muscles in piranhas derive from occipital somites given their innervation by true spinal nerves, ontogenetic studies remain essential to test this hypothesis.

\section{Acknowledgements}

The authors would like to thank Heidemarie Grillitsch for the line drawings in figures 1 and 4, Margaret Marchaterre from Neurobiology and Behavior at Cornell for technical support, John Friel from the Cornell Laboratory of Ornithology for providing red piranhas and several skeletons and Mark Sabaj, Department of Ichthyology, Academy of Natural Sciences, Philadelphia, for providing a black piranha skeleton (Serrasalmus specimen no 178557). This research was supported, in part, by the Austrian Science Fund and the US National Science Foundation (FWF grant 15873 to FL and NSF IBN9987341 to AHB).

\section{References}

- Barber SB, Mowbray WH (1956) Mechanism of sound production in the sculpin. Science 124: 219-220.

-Bass AH (1985) Sonic motor pathways in teleost fishes: a comparative HRP study. Brain Behav Evol 27:115-131

- Bass AH, Baker R (1990) Sexual dimorphism in the vocal control system of teleost fish: morphology of physiologically identified neurons. J Neurobiol 21:1155-1168.

-Bass AH, Baker R (1991) Evolution of homologous vocal control traits. Brain Behav Evol 38:240254.

Bass AH, Baker R (1997) Phenotypic specification of hindbrain rhombomeres and the origin of rhythmic circuits in vertebrates. Brain Behav Evol 50:3-16.

- Bass AH, Horvath BJ, Brothers E (1996) Nonsequential developmental trajectories lead to dimorphic vocal circuitry for males with alternative reproductive tactics. J Neurobiol 30: 493-504.

- Bass AH, Marchaterre MA, Baker R (1994) Vocalacoustic pathways in a teleost fish. J Neurosci 14:4025-4039.

-Carlson BA, Bass AH (2000) Sonic/vocal motor pathways in squirrelfish (Teleostei, Holocentridae). Brain Behav Evol 56:14-28.

$\checkmark$ Crawford JD, Huang X (1999) Communication signals and sound production mechanisms of mormyrid electric fish. J Exp Biol 202:14171426.

Fine ML, Ladich F (2003) Sound production, spine locking and related adaptations. In: Catfishes, Vol. 1. (Arratia G, Kapoor BG, Chardon M, Diogo R, eds), pp 249-290, Enfield, NH: Science Publishers.
Fine ML, King CB, Friel JP, Loesser KE, Newton S (1999) Sound production and locking of the pectoral spine of the channel catfish. Am Fish Soc Symp 24:105-114.

Finger TE, Kalil K (1985) Organization of motoneuronal pools in the rostral spinal cord of the sea robin, Prionotus carolinus. J Comp Neurol 239:384-390.

Fink SV, Fink WL (1996) Interrelationships of ostariophysan fishes. In: Interrelationships of Fishes (Stiassny MLJ, Pasenti LR, Johnson GD, eds), pp 209-249. San Diego: Academic Press.

Fish MP (1953) The production of underwater sounds by the northern seahorse, Hippocampus hudsonius. Copeia 1953:98-99.

- Goodson JL, Bass AH (2002) Vocal-acoustic circuitry and descending vocal pathways in teleost fish: convergence with terrestrial vertebrates reveals conserved traits. J Comp Neurol 448:298-322.

Hallacher LE (1974) The comparative morphology of extrinsic gasbladder musculature in the scorpionfish Genus Sebastes (Pisces: Scorpaenidae). Proc Cal Acad Sci 40:59-86.

Hawkins AD (1993) Underwater sound and fish behaviour. In: Behaviour of Teleost Fishes. (Pitcher TJ, ed), pp 129-169. London: Chapman and Hall.

Johnston CE, Johnson DL (2000) Sound production in Pimephales notatus (Rafinesque) (Cyprinidae). Copeia 2000:567-571.

Kastberger G (1981a) Economy of sound production in piranhas (Serrasalminae, Characidae): I. Functional properties of sonic muscles. Zool Jahrb Physiol 85:113-125.
Kastberger G (1981b) Economy of sound production in piranhas (Serrasalminae, Characidae): II. Functional porperties of sound emitter. Zool Jahrb Physiol 85:393-411.

- Kratochvil H (1978) Der Bau des Lautapparates vom Knurrenden Gurami (Trichopsis vittatus Cuvier \& Valenciennes) (Anabantidae, Belontiidae). Zoomorphologie 91:91-99.

Ladich F (1988) Sound production by the gudgeon, Gobio gobio L., a common European freshwater fish (Cyprinidae, Teleostei). J Fish Biol 32: 707-715.

Ladich F (1989) Sound production by the river bullhead Cottus gobio L. (Cottidae, Teleostei). J Fish Biol 35:531-538.

Ladich F (1997) Comparative analysis of swimbladder (drumming) and pectoral (stridulation) sounds in three families of catfishes. Bioacoustics 8:85-208

Ladich F (1999) Did auditory sensitivity and vocalization evolve independently in otophysan fishes? Brain Behav Evol 53:288-304.

Ladich F (2001) Sound-generating and -detecting motor system in catfish: design of swim bladder muscles in doradids and pimelodids. Anat Rec 263:297-306.

Ladich F (2004) Sound production and acoustic communication. In: The Senses of Fishes. Adaptations for the Reception of Natural Stimuli. (Van der Emde G, Mogdans J, Kapoor BG, eds), pp 210-230. New Delhi: Narosa Publ House.

Ladich F, Bass AH (1996) Sonic/vocal-acousticolateralis pathways in teleost fishes: a transneuronal neurobiotin study in mochokid catfish. J Comp Neurol 374:493-505. 
Ladich F, Bass AH (1998) Sonic/vocal motor pathways in catfishes: comparison with other teleosts. Brain Behav Evol 51:315-330.

Ladich F, Bass AH (2003) Underwater sound generation and acoustic reception in fishes with some notes on frogs. In: Sensory Processing in Aquatic Environments (Collin SP, Marshall NJ, eds), pp 173-193. New York: Springer.

- Ladich F, Fine ML (1992) Localization of pectoral fin motoneurons (sonic and hovering) in the croaking gourami Trichopsis vittatus. Brain Behav Evol 39:1-7.

- Ladich F, Fine ML (1994) Localization of swim bladder and pectoral motoneurons involved in sound production in pimelodid catfish. Brain Behav Evol 44:86-100.

Ladich F, Fine ML (in press) Sound generating mechanisms. In: Fish Communication (Ladich F, Collin SP, Moller P, Kapoor BG, eds). New Delhi: Narosa Publ. House.

Lanzing, WSR (1974) Sound production in the cichlid Tilapia mossambica Peters. J Fish Biol 6:341-347.

- Lindholm MM, Bass AH (1993) Early events in myofibrillogenesis and innervation of skeletal sound-generating muscle in a teleost fish. J Morphol 216:225-239.

Lundberg JG (1993) African-South American freshwater fish clades and continental drift: problem with a paradigma. In: Biological Relationship Between Africa and South America (Goldblatt P, ed), pp 156-199. New Haven CT: Yale Univ Press.
Mark1 H (1971) Schallerzeugung bei Piranhas (Serrasalminae, Characidae). Z Vergl Physiol 74: 39-56.

Nelson JS (1994) Fishes of the World (3rd ed). New York: John Wiley and Sons.

Ono RD, Poss SG (1982) Structure and innervation of the swim bladder musculature in the weakfish, Cynoscion regalis (Teleostei: Sciaenidae). Can J Zool 60:1955-1967.

Rauther M (1945) Über die Schwimmblase und die $\mathrm{zu}$ ihr in Beziehung tretenden somatischen Muskeln bei den Trigliden und anderen Scleroparei. Zool Jahrb Anat 69:159-250.

Salmon M, Winn HE, Sorgente N (1968) Sound production and acoustical behavior in triggerfish. Pac Sci 12:11-20.

Schaller F, Kratochvil H (1981) Lautbildung bei Fischen. Biologie in unserer Zeit 11:43-47.

- Schneider H (1964) Physiologische und morphologische Untersuchungen zur Bioakustik der Tigerfische (Pisces, Theraponidae). Z Vergl Physiol 47:493-558.

Stabentheiner A (1988) Correlations between hearing and sound production in piranhas. J Comp Physiol A 162:67-76.

Stout JF (1963) The significance of sound production during the reproductive behaviour of Notropis analostanus (Family Cyprinidae). Anim Behav 11:83-92.
Takayama M, Onuki A, Yosino T, Yoshimoto M, Ito H, Kohbara J, Somiya H (2003) Sound characteristics and the sound producing system in silver sweeper, Pempheris schwenkii (Perciformes: Pempheridae). J Mar Biol Assoc UK 83:4062/1-4

Tavolga WN (1962) Mechanism of sound production in the ariid catfish Galeichthys and Bagre. Bull Am Mus Nat Hist 24:1-30.

Tracy HC (1959) Stages in the development of the anatomy of motility of the toadfish (Opsanus tau). J Comp Neurol 111:27-81.

- Tracy HC (1961) Development of the spinal crest, nerves and muscles in the toadfish (Opsanus tau). J Comp Neurol 116:291-315.

Vance TL, Hewson JM, Modla S, Connaughton MA (2002) Variability in sonic muscle size and innervation among three sciaenids: spot, Atlantic croaker, and weakfish. Copeia 2002: 1137-1143.

Wilson B, Batty RS, Dill LM (2004) Pacific and Atlantic herring produce bursts pulse sounds. Proc R Soc Lond B (suppl) 271:95-97.

Winn HE, Marshall JA (1963) Sound-producing organ of the squirrelfish, Holocentrus rufus. Physiol Zool 36:36-44.

Yoshimoto M, Kikuchi K, Yamamoto N, Somiya $\mathrm{H}$, Ito H (1999) Sonic motor nucleus and its connections with octaval and lateral line nuclei of the medulla in a rockfish, Sebastiscus marmoratus. Brain Behav Evol 54:183-204. 